www.jmscr.igmpublication.org

Impact Factor 5.84

Index Copernicus Value: 71.58

ISSN (e)-2347-176x ISSN (p) 2455-0450

crossref DOI: _https://dx.doi.org/10.18535/jmscr/v5i12.76

Journal Of Medical Science And Clinical Research

\title{
Hepatocellular Carcinoma with Bile Duct Tumor Thrombi (Icteric Hepatoma)- A 19 Year Experience from a Tertiary Care Centre
}

\author{
Authors \\ Dr K. Sathish Kumar ${ }^{1}$, Dr S.Jeswanth ${ }^{2}$, Dr P. Ravichandran ${ }^{3}$, Dr C. Sugumar ${ }^{4}$, \\ Dr R. Prabhakaran ${ }^{5}$, Dr P. Senthil Kumar ${ }^{6}$, Dr R.Kamalakannan ${ }^{7}$ \\ ${ }^{1}$ Resident, ${ }^{2,4}$ Professor, ${ }^{3}$ Director and Head of the Department, ${ }^{5,6,7}$ Assistant Professor \\ Institute of Surgical Gastroenterology and Liver Transplant, Government Stanley Medical College and \\ Hospital, Chennai
}

\begin{abstract}
Introduction/Objective: Hepatocellular carcinoma presenting with obstructive jaundice due to bile duct tumor thrombi is a rare entity, with a reported incidence worldwide of about 1 to $12 \%$. The objective of this study is to analyse the clinicopathological and post-surgical outcomes in patients who had hepatocellular carcinoma with bile duct tumor thrombi.
\end{abstract}

Materials and Methods: 42 cases of pathologically proven Hepatocellular carcinoma with bile duct tumor thrombi in non-cirrhotic liver, who underwent hepatectomies at Institute of Surgical Gastroenterology and Liver Transplant, Government Stanley Medical College and hospital, between January 1997 and September 2016 were analysed retrospectively. Clinicopathological, biochemical, radiological, operative variables and post-operative morbidity and mortality were analysed.

Results: Pre-operative AFP were elevated in 28 patients (> $400 \mathrm{ng} / \mathrm{ml}$ ). Right hepatectomy with thrombectomy and $T$ tube drainage, extended right hepatectomy with bile duct excision, left hepatectomy, extended left hepatectomy with bile duct excision, left lateral segmentectomy were done in 17,11,10,2 and 2 patients respectively. 14 patients had significant post-operative morbidity while mortality was seen in three patients. Median survival was about 27.2 months. Tumor recurrence was observed in 28 of 42 cases (66.67\%) with a median time to recurrence of about 10.3 months.

Conclusion: Bile duct tumor thrombi does not preclude hepatic resection and these patients who are otherwise fit to undergo hepatectomy are offered surgery as the first line treatment.

Keywords - hepato cellular carcinoma, obstructive jaundice, bile duct tumor thrombi.

\section{Introduction}

Hepatocellular carcinoma (HCC) is still being considered as the third leading cause of cancer related death worldwide ${ }^{(1)}$. The mainstay of curative treatment is surgical resection. HCC presenting as obstructive jaundice is uncommon. The reported incidence of bile duct tumor thrombus varies from $0.53-12.9 \%(2-8)$. There is a paucity of literature available regarding the prognostic significance of BDTT in HCC and the outcomes after surgical resection. In this study, we retrospectively analysed the various clinico pathological factors and outcomes following surgical resection in patients presenting with obstructive jaundice due to macroscopic bile duct tumor thrombi in a non cirrhotic liver. 


\section{JMSCR Vol||05||Issue||12||Page 31741-31748||December}

\section{Materials and Methods}

All patients who underwent liver resection with a curative intent for HCC between Jan 1997 to sep 2016 at the Institute of Surgical Gastroenterology \& Liver Transplantation, Stanley Medical College Hospital, Chennai, India were retrospectively analysed. Out of $(426+200$ ?) patients who underwent liver resections for HCC, 42 of them were diagnosed to have HCC with BDTT .The presence of BDTT were confirmed pathologically post operatively in all these cases.

All cases underwent basic blood investigations which included liver function tests and screening for hepatitis B and C viruses. Imaging was done initially with ultra sound abdomen followed by contrast enhanced CT abdomen ( Fig 1,2 ). MRI/MRCP was used to evaluate the extent of BDTT ( Fig 3).

Fig: (1,2): CECT Abdomen showing tumour thrombus in CBD.
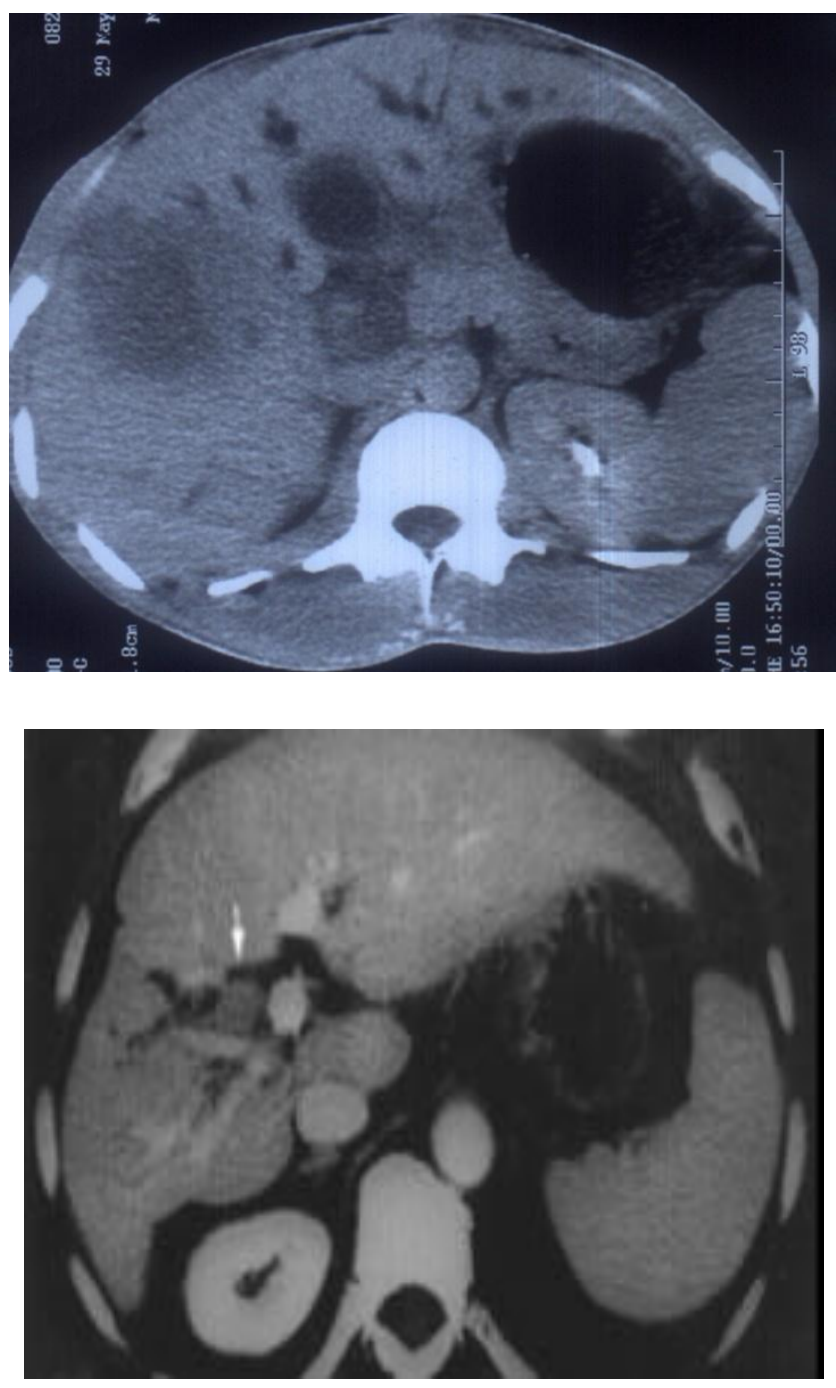

Fig (3) MRCP image showing tumour thrombus
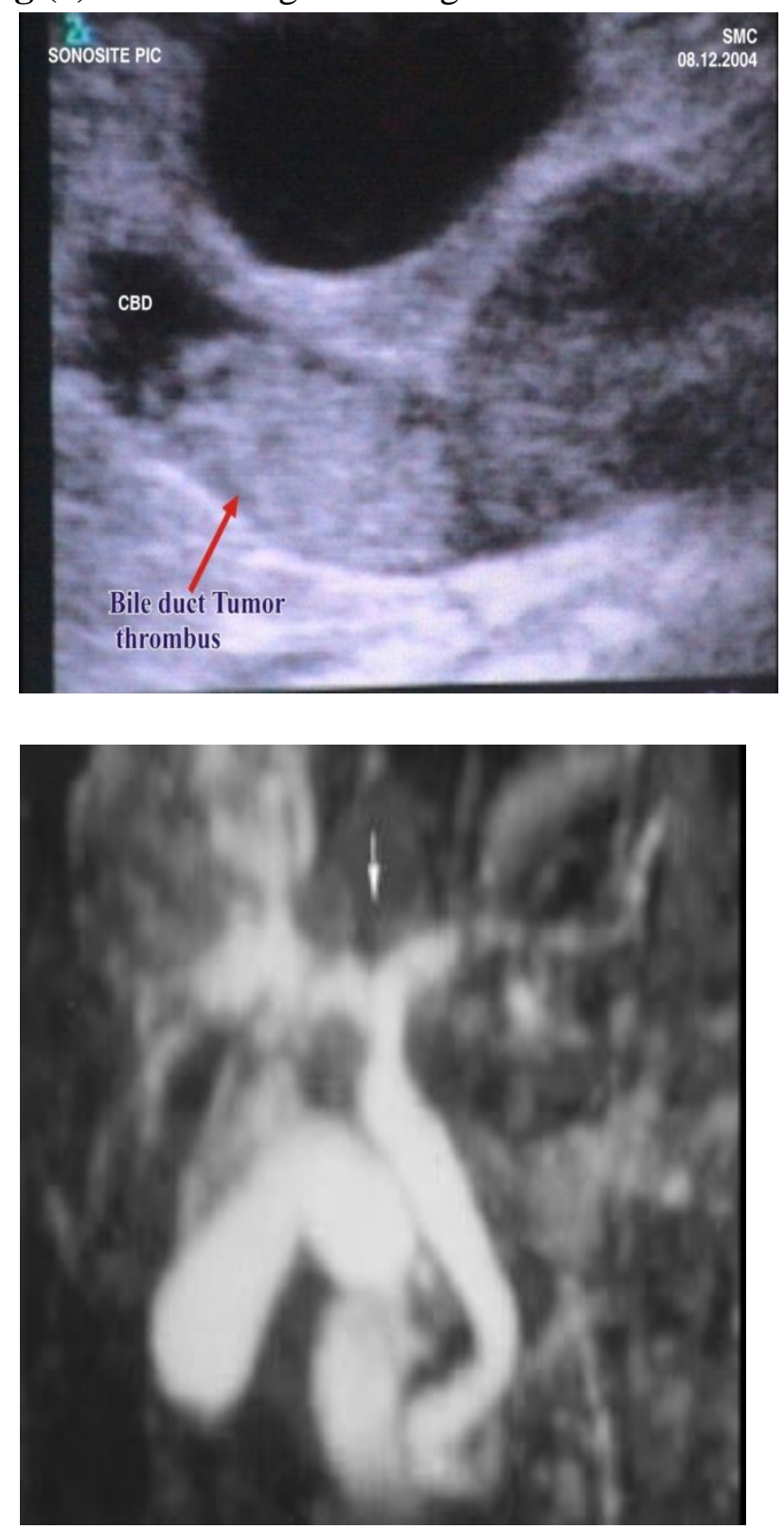

Pre operative biliary drainage was done selectively for patients with bilirubin $>5 \mathrm{mg} / \mathrm{dl}$ or patients who presented with cholangitis. Percutaneous Transhepatic Biliary Drainage (PTBD) was the preferred method for biliary drainage at our institute. All 42 patients underwent formal anatomical resections for the primary tumor. The choice of the surgical procedure was based upon the general condition of the patient, location and number of the primary tumor, residual liver volume and pre operative LFT status. For BDTT, if the tumor thrombus was found free-floating in the bile duct then a choledochotomy was done and tumor thrombus 
extricated. Bile duct resection was done only for cases with tumor invasion of the bile duct near the confluence and for large bile duct tumor thrombi. Biliary enteric anastomosis in the form of hepaticojejunostomy was done following resection of extra hepatic bile duct. Tumor size, number, margin status, characteristics of the tumor thrombi, blood loss and operating time were the variables noted. BDTT was classified according to the location as proposed by Ueda et al $-{ }^{(9)}$ \{Type $1:$ Involving the second order intrahepatic duct, Type 2: Involving the first-order intrahepatic duct, Type 3a: Extending to the hepatic confluence, Type 3b: Implanted tumour growing in CHD \& Type 4: dislodged BDTT within the CHD \}(Fig 4).
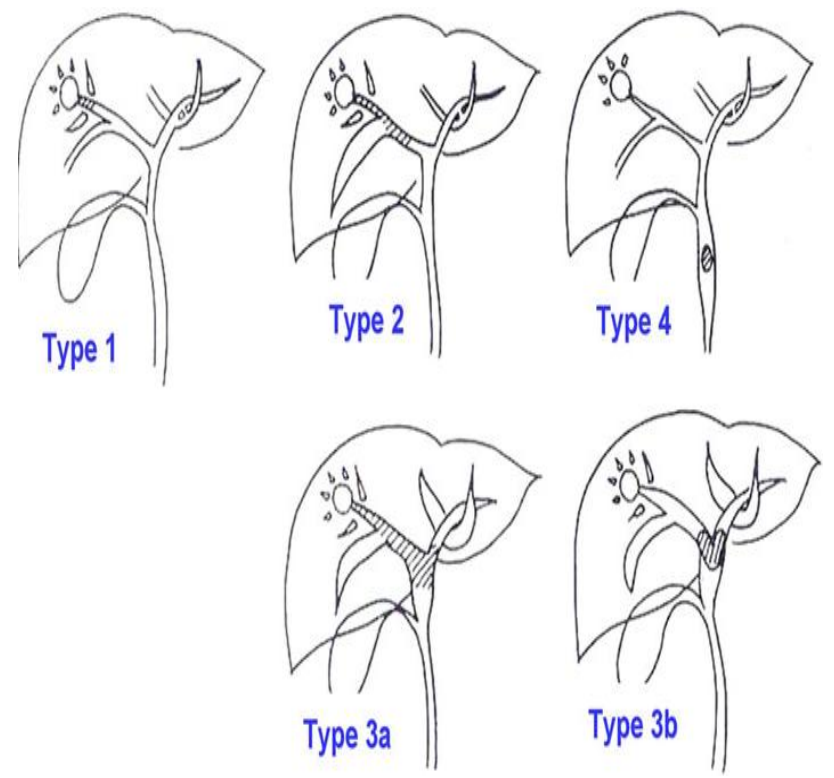

Post operative complications pertaining to liver resections like bile leak, post hepatectomy liver failure and sepsis were noted. Post hepatectomy liver failure was defined as elevated serum bilirubin and prolonged prothrombin time on or after 5th post operative day. Peri operative mortality was defined as mortality occurring within 30 days of surgery. Patients were followed up every 3 months for first 2 years and every 6 months for next 3 years. AFP levels and USG evaluation were done at 3 monthly interval and CECT abdomen done at 6 monthly interval during follow up.

\section{Statistical Analysis}

Numerical variables were expressed as mean+/$\mathrm{SD}$ and nominal variables as percentage. Kaplen

Meir method was used for survival analysis.

\section{Results}

Demographic data of 42 cases are summarized in Table - 1. We observed that HCC with BDTT was commonly seen in male patients and the mean age of presentation was about 54.9 years. Liver function tests and AFP values are summarized in Table - 2. 50\% (21 cases) presented with obstructive jaundice at initial presentation. Mean bilirubin was about $6.2 \mathrm{mg} / \mathrm{dl}$. About $2 / 3 \mathrm{rd}$ of the cases had an AFP value of more than $400 \mathrm{ng} / \mathrm{ml}$ at diagnosis.

Table - 3 summarizes the various surgical procedures undergone by these 42 cases who had HCC with BDTT. Right hepatectomy with tumor thrombectomy through a choledochotomy with $\mathrm{T}$ tube drainage was the common procedure performed. 12 cases underwent concomitant extra hepatic bile duct excision with bilio enteric anastomosis. Table- 4 summarizes the operative variables and the tumor thrombi classification based on the classification given by Ueda et al. Type III a was the most common type and type III b was the least common type noted.

Fig: 5- Post operative Left hepatectomy specimen with bile duct excision showing a tumor thrombus in the $\mathrm{CBD}$

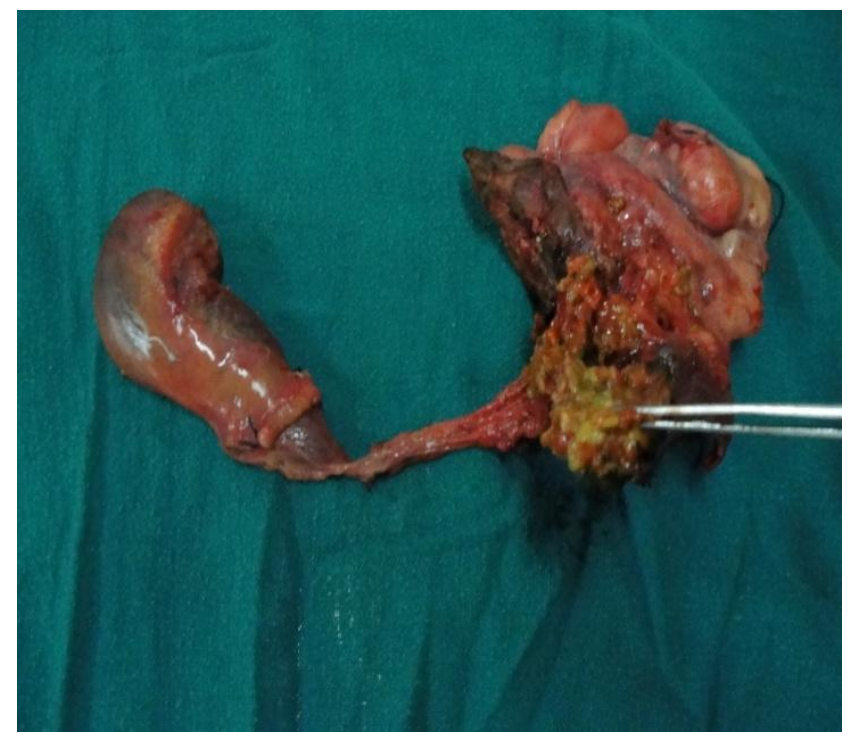




\section{JMSCR Vol||05||Issue||12||Page 31741-31748||December}

Duration of surgery (Table 5) and post operative complications are depicted (Table 6). Post operative morbidity was encountered in 14 cases $(33.33 \%$ ) (Table -7). Bile leak was noted in 4 cases. All the 4 cases were managed conservatively while 2 of them required percutaneous drainage of the collection. Post hepatectomy liver failure was noted in 5 cases. Length of hospital stay on an average was about 16.3 days. Perioperativemotality was about $7.14 \%$. (3 cases ) due to post hepatectomy liver failure.

Table -8 depicts the histopathological data of 42 cases. Positive margins were seen in 4 cases. Vascular invasion was noted in 12 cases. There were nil cases with lymph node positivity. Poorly differentiated HCC was seen in about \% of cases . Median follow up for these cases was about 30 months, ranging from 3 months to 70 months (Table -9). Median survival was about 27.2 months with aone, three and five year survival rate of about $81 \%, 47 \%, 9 \%$ respectively (Fig 6). Tumor recurrence was observed in 28 of 42 cases $(66.67 \%)$ with a median time to recurrence of about 10.3 months. Most common site of recurrence was the remnant liver parenchyma. Recurrences were managed with loco regional therapies.

Fig: 6 - Kaplen Meir survival analysis

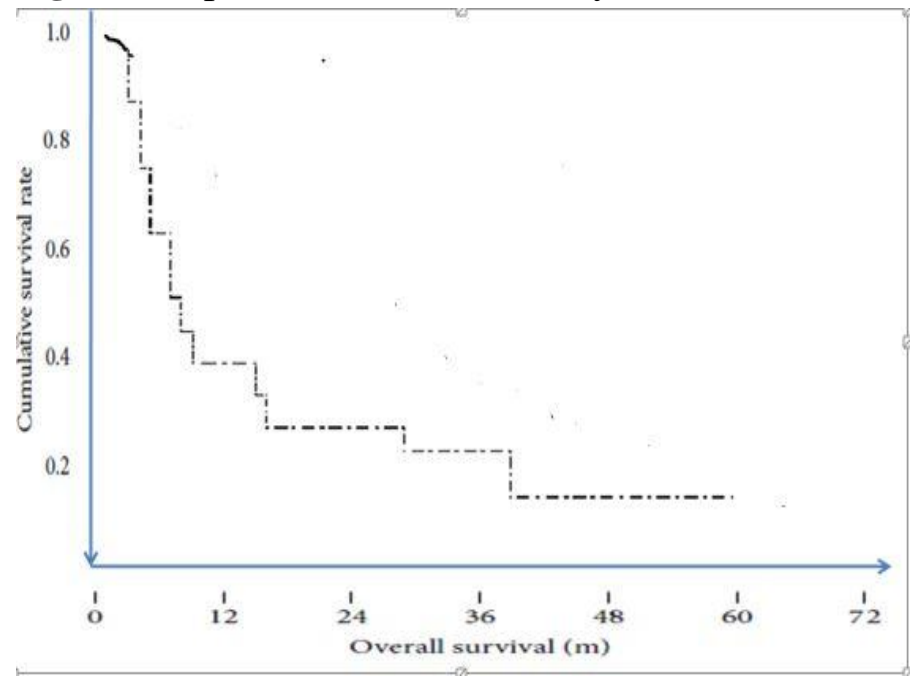

Table 1

\begin{tabular}{|c|c|}
\hline & $\begin{array}{l}\text { BDTT } \\
n=42\end{array}$ \\
\hline Age (yrs) & $54.9 \pm 7.3$ \\
\hline Males/Females & $31 / 11$ \\
\hline \multicolumn{2}{|l|}{$\mathrm{n}$} \\
\hline $\begin{array}{c}\text { HBV Positive } \\
n(\%)\end{array}$ & $7(16.67 \%)$ \\
\hline $\begin{array}{c}\text { HCV Positive } \\
n(\%)\end{array}$ & $2(4.76 \%)$ \\
\hline Jaundice at presentation $n(\%)$ & $21(50 \%)$ \\
\hline CTP Class A /B (\%) & $\begin{array}{c}30(71.43 \%) / 12 \\
(28.57 \%)\end{array}$ \\
\hline
\end{tabular}

Table - 2

\begin{tabular}{cc}
\hline & $\begin{array}{c}\text { BDTT } \\
\mathbf{n = 4 2}\end{array}$ \\
\hline S.Bilirubin (mg/dl) & $6.2 \pm 3.5$ \\
S. AST (IU/L) & $98.8 \pm 20$ \\
S. Alkaline Phosphatase \\
(IU/L) \\
S.Albumin (g/dl) \\
AFP (> 400ng/ml)
\end{tabular}

Table - 3

\begin{tabular}{cc|}
\hline Operative Procedure & $\mathbf{N}=\mathbf{4 2}$ \\
\hline $\begin{array}{c}\text { Right Hepatectomy with thrombectomy through } \\
\text { Choledochotomy and T tube drainage }\end{array}$ & 17 \\
\hline $\begin{array}{c}\text { Extended Right Hepatectomy with Extra hepatic bile duct } \\
\text { excision }\end{array}$ & 11 \\
\hline Left Hepatectomy with thrombectomy & 9 \\
\hline Left hepatectomy with bile duct excision & 1 \\
\hline Extended Left Hepatectomy with thrombectomy & $\mathbf{2}$ \\
\hline Left Lateral Segmentectomy with thrombectomy & $\mathbf{2}$ \\
\hline
\end{tabular}

Table - 4

\begin{tabular}{|c|c|c|}
\hline \multicolumn{2}{|l|}{ Tumour } & \\
\hline \multicolumn{2}{|l|}{ Number } & $2 \pm 1$ \\
\hline \multicolumn{2}{|l|}{ Size (cms) } & $5.6 \pm 3.2$ \\
\hline \multicolumn{3}{|c|}{ UEDA Classfication } \\
\hline & I & 4 \\
\hline & $\|$ & 9 \\
\hline & Illa & 19 \\
\hline & $\| l l b$ & 2 \\
\hline & IV & 8 \\
\hline
\end{tabular}


Table 5

BDTT

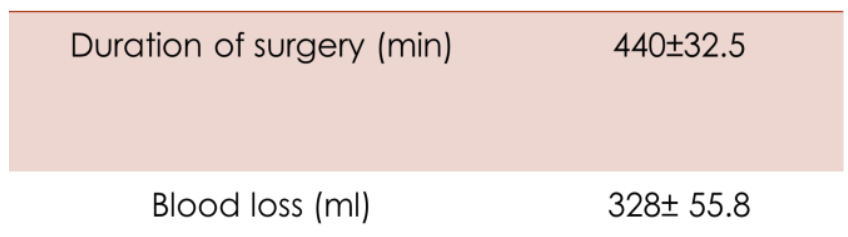

\section{Table6}

\begin{tabular}{|l|l|c|}
\hline $\begin{array}{l}\text { S.N } \\
\text { 0 }\end{array}$ & Complications & Number \\
\hline 1. & Bile leak & 4 \\
\hline 2. & Post hepatectomy liver failure & 5 \\
\hline 3. & Post op wound sepsis & 8 \\
\hline 4. & $\begin{array}{l}\text { Pulmonary complications } \\
\text { including effusion }\end{array}$ & 7 \\
\hline 5. & Peri operative mortality & 3 \\
\hline
\end{tabular}

\section{Table 7}

\begin{tabular}{cc}
\hline $\begin{array}{c}\text { BDTT } \\
\mathbf{n = 4 2}\end{array}$ \\
\hline $\begin{array}{c}\text { Morbidity } \\
\text { Length of hospital stay } \\
\text { (Days) }\end{array}$ & $14(33.33 \%)$ \\
\hline Mortality & $16.3 \pm 5.7$ \\
\hline
\end{tabular}

\section{Table 8}

\begin{tabular}{|l|c|}
\hline $\begin{array}{l}\text { Tumor differentiation - well / } \\
\text { moderate / poor }\end{array}$ & 10/17/15 \\
\hline Positive margins & 4 \\
\hline Lymphnode +Ve & nil. \\
\hline Vascular invasion & 12 \\
\hline
\end{tabular}

\section{Table - 9}

\begin{tabular}{lc}
\hline Survival & BDTT \\
\hline Median Survival (months) & 27.2 \\
& \\
\hline
\end{tabular}

OS (\%)

\begin{tabular}{cc}
1 year & 81 \\
3 Years & 47 \\
5 Years & 9 \\
\hline
\end{tabular}

\section{Discussion}

Icteric hepatomas was first described in 1949 (10). The proper diagnosis and management of HCC with BDTT has been a challenge ever since their first description. HCC with BDTT is not a common entity with a reported incidence being 0.53 to $12.9 \%$. In our study the incidence of hepatocellular carcinoma with BDTT was $11 \%$ and all of them underwent liver resection.

Surgical treatment with a curative intent remains the only hope for these subset of patients. Oba et $\mathrm{al}^{(11)}$ and Luo et $\mathrm{al}^{(12)}$ found that HCC with BDTT respond poorly to non surgical management like TACE/PTBD/radiotherapy. 1,3,5 year overall survival rates were $14,5,0 \%$ according to Oba et al after non surgical management. Similarly Luo et al reported a median survival of about 5 months for non surgical management with $0 \% 5$ year overall survival. In contrast, our study had a median survival of 27.2 months following surgical resection. This clearly illustrates that surgical resection remains the mainstay and first choice of treatment for patients with HCC with BDTT whenever feasible.

Evaluation of hepatic reserves in these patients is quite tricky and challenging due to the presence of obstructive jaundice. The Child Pugh's score may be high initially due to presence of obstructive jaundice and the resultant liver dysfunction. But usually the liver function improves following biliary decompression ${ }^{(13,14,15)}$. Most of the studies in literature supports the fact that HCC with bile duct invasion have worse prognosis than HCC without bile duct invasion. ${ }^{(16,17,18,19)}$. Long term survival in patients with HCC and BDTT is significantly less than patients without bile duct tumor thrombi. This may be due to the fact that the tumor has a more aggressive tumor biology.

One of the reason for poor outcomes in these subset of patients in all studies including our study was due to a very high incidence of post operative tumor recurrence especially in the remnant liver. We observed a recurrence rate of about $66.67 \%$ with a median time to recurrence of about 10.2 months. Recurrences are usually classified as 
early ( $<1$ year ) and late ( $>1$ year ) after resection. Early recurrence has been associated with poor prognosis ${ }^{(20)}$. Ikenga et $\mathrm{al}^{(17)}$, Qin et al ${ }^{(7)}$, Noda et al $^{(21)}$, Shao et al ${ }^{(22)}$ and Zeng et al ${ }^{(18)}-$ all these studies reported $>50 \%$ recurrence in less than one year. In our study we observed early recurrence in 20 cases. Postulated causes for poor prognosis and recurrence is the high incidence of vascular invasion and poor tumor differentiation observed in these cases. It was thought that early recurrence is due to intra hepatic metastasis from primary tumor via venous circulation ${ }^{(20)}$. Vascular invasion may contribute to early recurrence. But in our study only 12 out of 42 cases cases had evidence of vascular invasion on histopathology. Recurrences were noted even in cases without vascular invasion. Shao et $\mathrm{al}^{(22)}$ and Ikenaga et al (17) demonstrated tumor recurrences in cases without evidence of major vascular invasion. This indicates that dissemination via bile duct route could be another possible cause for recurrence.

Whether to do routine extra hepatic concomitant bile duct resection for all cases with HCC and BDTT is still controversial. Some authors including ourselves found that bile duct tumor thrombus rarely invade the bile duct wall near the hepatic hilum and hence could be easily removed through choledochotomy, routine bile duct excision was not recommended. Overall survival did not seem to improve significantly with bile duct excision ${ }^{(4,5,21,23)}$. Hence these authors suggested routine bile duct excision be avoided. In our study bile duct excision was done in only 12 out of 42 cases. Recurrence in remnant bile duct was observed in only one case in our study. But some other authors ${ }^{(18,24)}$ suggested routine bile duct excision eradicates microscopic tumor in the bile duct and thereby decrease the recurrence. Since all these studies involve only small number of cases further research is needed with larger patients before a consensus could be arrived regarding recommendation of bile duct excision in patients with HCC and BDTT.

Experiences and outcomes after liver transplantation for cases with HCC and BDTT is limited in literature. Hwang et $\mathrm{al}^{(25)}$ reported an overall survival of $50 \%$ in a cohort of 14 patients. Further studies are needed in this regard too before reaching a consensus on liver transplantation for cases with HCC with BDTT.

\section{Conclusion}

Hepato cellular carcinoma with bile duct tumor thrombus has an overall poor survival when compared to cases with hepatocellular carcinoma without bile duct tumor thrombi. However surgical treatment inthe form of liver resection with a curative intent can offer significant survival benefit for selected cases when compared to non surgical management. Hence the mere presence of BDTT should not be a deterrent for major hepatic resections. Since these patients have a high rate of recurrence more effective adjuvant therapies are warranted in future for better outcomes.

\section{References}

1. Llovet JM, Burroughs A, Bruix J. Hepatocellular carcinoma. Lancet. 2003;362:1907-17

2. Kojiro M, Kawabata K, Kawano Y, Shirai F, Takemoto N, Nakashima T. Hepatocellular carcinoma presenting as intrabile duct tumor growth: a clinicopathologic study of 24 cases. Cancer. 1982;49:2144-7.

3. Huang JF, Wang LY, Lin ZY, Chen SC, Hsieh MY, Chuang WL, et al. Incidence and clinical outcome of icteric type hepatocellular carcinoma. J Gastroenterol Hepatol. 2002;17:190-5.

4. Satoh S, Ikai I, Honda G, Okabe H, Takeyama O, Yamamoto $\mathrm{Y}$, et al.Clinicopathologic evaluation of hepatocellular carcinoma with bile duct thrombi. Surgery. 2000;128:779-83.

5. Shiomi M, Kamiya J, Nagino M, Uesaka $\mathrm{K}$, Sano T, Hayakawa N, et al. Hepatocellular carcinoma with biliary tumor thrombi: aggressive operative 
approach after appropriate preoperative management. Surgery. 2001;129:692-8.

6. Peng SY, Wang JW, Liu YB, Cai XJ, Xu B, Deng GL, et al. Hepato cellular carcinoma with bile duct thrombi: analysis of surgical treatment. Hepatogastroenterology. 2004;51:801-4.

7. Qin LX, Ma ZC, Wu ZQ, Fan J, Zhou XD, Sun HC, et al. Diagnosis and surgical treatments of hepatocellular carcinoma with tumor thrombosis in bile duct: experience of 34 patients. World $\mathbf{J}$ Gastroenterol. 2004;10:1397-401.

8. Yeh CN, Jan YY, Lee WC, Chen MF. Hepatic resection for hepatocellular carcinoma with obstructive jaundice due to biliary tumor thrombi. World JSurg. 2004;28:471-5.

9. Ueda $\mathrm{M}$, Takeuchi $\mathrm{T}$, Takayasu $\mathrm{T}$, Takahashi K, Okamoto S, Tanaka A. Classification and surgical treatment of hepatocellular carcinoma (HCC) with bile duct thrombi. Hepatogastroenterology 1994; 41: 349-354

10. Mallory TB, Castleman B, Parris EE. Case records of the Massachusetts General Hospital. N Eng J Med 1947; 237: 673676

11. Oba A, Takahashi S, Kato Y, Gotohda N, Kinoshita T, Shibasaki H, et al.Usefulness of resection for hepatocellular carcinoma with macroscopic bileduct tumor thrombus. Anticancer Res. 2014;34:4367-72.

12. Xiangji L, Weifeng $\mathrm{T}$, Bin $\mathrm{Y}$, Chen $\mathrm{L}$, Xiaoqing J, Baihe Z, et al. Surgery of hepatocellular carcinoma complicated with cancer thrombi in bile duct:

13. Shiomi M, Kamiya J, Nagino M, Uesaka K, Sano T, Hayakawa N,et al. Hepatocellular carcinoma with biliary tumor thrombi: aggressive operative approach after appropriate preoperative management. Surgery 2001;129:692-698.

14. Moon DB, Hwang S, Wang HJ, Yun SS, Kim KS, Lee YJ, Kim KH, Park YK
Surgical Outcomes of Hepatocellular Carcinoma with Bile Duct Tumor Thrombus: A Korean Multicenter Study. World J Surg 2013; 37:443-451

15. Yeh CN, Jan YY, Lee WC, Chen MF: Hepatic resection for hepatocellular carcinoma with obstructive jaundice due to biliary tumor thrombi. World J Surg 2004;28:471-475.

16. Y, Hatano E, Seo S, Taura K, Yasuchika $\mathrm{K}$, Uemoto S. Hepatocellular carcinoma with bile duct tumor thrombus: surgical outcomes and the prognostic impact of concomitant majorvascular invasion. World J Surg 2015;39:1485-1493

17. Ikenaga N, Chijiiwa K, Otani K, Ohuchida J, Uchiyama S,Kondo K. Clinicopathologic characteristics of hepatocellular carcinoma with bile duct invasion. J GastrointestSurg 2009;13:492-497.

18. Zeng H, Xu LB, Wen JM, Zhang R, Zhu MS, Shi XD, et al. Hepatocellular carcinoma with bile duct tumor thrombus: a Clinicopathological analysis of factors predictive of recurrence andoutcome after surgery. Medicine (Baltimore) 2015; 94:e364

19. Xiangji L, Weifeng T, Bin Y, Chen L, Xiaoqing J, Baihe Z, etal. Surgery of hepatocellular carcinoma complicated with cancerthrombi in bile duct: efficacy for criteria for different the rapymodalities. Langenbecks Arch Surg 2009;394:10331039

20. Poon RT, Fan ST, Ng IO, Lo CM, Liu CL, Wong J. Different risk factors andprognosis for early and late intrahepatic recurrence after resection of hepatocellular carcinoma. Cancer. 2000;89:500-7.

21. Noda T, Nagano H, Tomimaru Y, Murakami M, Wada H, Kobayashi S, et al.Prognosis of hepatocellular carcinoma with biliary tumor thrombi after liversurgery. Surgery. 2011;149:371-7 
22. Shao W, Sui C, Liu Z, Yang J, Zhou Y. Surgical outcome of hepatocellular carcinoma patients with biliary tumor thrombi. World J Surg Oncol. 2011;9:2

23. Yamamoto $S$, Hasegawa $K$, Inoue $Y$, Shindoh J, Aoki T, Sakamoto Y, et al. Bileduct preserving surgery for hepatocellular carcinoma with bile duct tumorthrombus. Ann Surg. 2015;261:e123-5

24. Wong TC, Cheung TT, Chok KS, Chan AC, Dai WC, Chan SC, et al. Outcomes of hepatectomy for hepatocellular carcinoma with bile duct tumourthrombus. HPB (Oxford). 2015;17:401-8.

25. Ha TY, Hwang S, Moon DB, Ahn CS, Kim KH, Song GW, et al. Longtermsurvival analysis of liver transplantation for hepatocellular carcinoma withbile duct tumor thrombus. Transplant Proc. 2014;46:774-7. 